\section{New Journals review supplement 1994}

CRITERIA for journals to be considered for review in this issue were circulated to publishers earlier this year, and were also published in Nature. They were that:

(1) the first number appeared during or after June 1992 and at least four separate numbers were issued by the end of April 1994 (although some of the journals eligible for, but not covered in, last year's review issue were also considered) ${ }^{*}$;

(2) the journal is published at least three times a year;

(3) the main language used is English;

(4) where possible at least four issues should be made available for review, including the first and the most recent numbers.

The time criteria ensure that a reasonable sample of issues is available for judgement by the time reviews are commissioned.

Several journals known to satisfy the criteria were not submitted for review, or arrived too late for inclusion. It proved difficult to find reviewers for other, doubtless worthy journals, while some titles were considered to be of marginal interest to Nature's audience. Journals covering any aspect of science

\section{Science in society}

\section{Jon Turney}

Perspectives on Science: Historical, Philosophical, Social. Editor Joseph C. Pitt. University of Chicago Press. 4/yr. $\$ 70$ (institutional); $\$ 35$ (personal).

Science and Education: Contributions from History, Philosophy and Sociology of Science and Mathematics. Editor Michael R. Matthews. Kluwer. 4/yr. DFL341, \$169 (institutional); DFL162, $\$ 93$ (personal).

As the subtitles indicate, both these journals aim to carve new niches in the burgeoning field of science studies. Both are also trying to speak across disciplines. Perspectives on Science is for all those pondering how and why science gets done, and how scientific knowledge is validated. The editorial premise is that "a comprehensive and deep understanding of science" requires more interaction between historical, philosophical and sociological studies. Science and Education is trying to apply the insights of scholars in science studies to help people teaching real science.

Worthy projects both, and ones that give both journals a great range of subject matter, so obtaining decent contributions is no problem. Not so easy to deliver are genuine interdisciplinarity and a sense of were eligible, although those dealing with clinical medicine, engineering and pure mathematics were excluded, as were abstracts publications and newsletters. A list of titles eligible for review but not covered appears on page 458 .

The brief given to the reviewers was to limit themselves to comments on the publications sent to them, and to avoid discussion of general questions of periodical publishing. Opinions expressed in the reviews are based on a sample of issues, and apply to mid-1993 at the latest. As in previous years, the preponderance of journals in the biological sciences reflects the bias of material submitted.

Details of editors and frequency of publication, and the subscription rates appearing at the top of each review, are given in most instances for 1994. This information is not complete in all cases, and readers interested in subscribing to a particular journal should check the rate with the publisher concerned.

*See Nature 365, 569-589 (1993); 359, 347, 581-599 (1990); 341, 350-370 (1989); 335; 459-478 (1988); 329, 357-376 (1987); 323, 359-379 (1986).

\section{a coherent project.}

Here, Perspectives, the newer of the two, is somewhat ahead, although not quite there yet. Many of the (rather long) papers are of general interest, covering such topics as positivism as the organizational myth of science (Stephan Fuchs) or print and early modern science (Henry Lowood and Robin Rider). The ones that are mainly historical often break new ground, as in Allen Harris's yet to be completed account of the Chomskyan revolution in linguistics. There is, though, a dearth of distinctively sociological contributions, despite the presence of several leading sociologists of science among the advisory editors. Do sociologists of scientific knowledge prefer to stick to their own journals, rather than submit papers to one where their fundamental assumptions are occasionally questioned? Or is this just because there are many more historians?

Contributors to Science and Education are also mostly dismissive of the stronger claims that knowledge is socially determined. Otherwise, they have less in common than I had hoped. The articles range from lengthy foundation discussions of the cultural meaning of science education to accounts of classroom use of particular historical episodes, with a sprinkling of inaccessible older papers reprinted. As it stands, the journal may have cast its net slightly too wide to develop into a satisfactory package. Lewis Pyenson's reflections 435-464 (1992); 353, 457-481 (1991); on the history of history of science, for example, are thought-provoking, but would be better placed in a journal that addresses the profession more directly.

At the same time, ironically, it has a limitation often found in discussion of science studies and science teaching. In the four issues offered for review, science is physics. I hope the editor can find some contributors prepared to treat the other sciences. A look at Perspectives on Science might suggest some possible authors, if none can be found elsewhere.

Jon Turney is in the Department of History, Philosophy and Communication of Science, University College London, Gower Street, London WC1E 6BT, UK.

\section{Après moi le déluge}

Arthur M. Lesk

Structure: Form and Function in Modern Biology. Editors Wayne A. Hendrickson and Carl-Ivar Brändén. Current Biology. 12/yr. \$504.50, £298 (institutional); $\$ 113.50$, £77.95 (personal); \$64.45, $£ 42.95$ (student).

THE increasing flow of protein structures has generated a need for new outlets, leading to the expansion of existing journals and the creation of new ones. When creating new ones, editors and publishers can tailor the contents and format to the current state of the field. Structure is one of the more attractive newcomers, both physically and intellectually, in the field of structural biology.

Structure publishes several categories of papers. Research articles occupy most of its space, and most of these present new protein structures, determined by X-ray crystallography or nuclear magnetic resonance. A minority of articles contain purely computational analysis or technical methods. Reviews and mini-reviews are sometimes linked to research articles, as in Nature's News and Views, but often stand alone. Occasional features are book reviews and a section called "Ways \& Means" that discusses technical matters. Georges Cohen has written a "Personal Reflections" piece on $\beta$-galactosidase, and others are promised.

A regular feature that is unusual and useful is "Paper Alert", which contains abstracts of articles appearing in other journals and occasionally more extended discussions of a selected one. Each issue features a calendar of meetings. In all, Structure is a journal that one can read with interest from cover to cover.

The editors have chosen sensible length limits for articles. Elsewhere, protein structures have sometimes been reported in short letters that whet but do not satisfy the reader's appetite, or in long technical 